\title{
An Inclusive Approach to Technology Development and Technology Project Implementations
}

\author{
Maruti Vitthal Khaire \\ (National Engineering Industries Ltd. \& TAPMI School of Business, Manipal University, Jaipur, India)
}

\begin{abstract}
New technology development projects are having risks, uncertainties, complexities and long development time involved in addition to resources required to invest into innovation projects. Lack of inclusive disciplined approach and structured innovation process around the selection of new technology projects, reduces the probabilities of innovation project's success. The present paper suggests inclusive approach to technology development and implementation to achieve set of strategic technology objectives of the organization. It suggests inclusive approach to facilitate systematic technology development, set direction for innovations, and implement robust strategy for technology development and implementation. Organization portfolio assessment, building technology roadmap and use of technology project management approach for successfully implement the developed technology to gain commercial success. The approach suggested in present work will serve as guidelines for technology managers, business managers and top management to list, select, prioritize, develop and implement the new technologies in organizations.
\end{abstract}

Keywords: Technology Roadmap, Portfolio Analysis,

\section{Introduction}

In recent business crises time, it is common to discuss about either new technologies (innovation) projects or current running projects to be given priority in most of the discussion forums. Most commonly even C Level executives makes comments that new technology development projects are good to have it in portfolio, however, expected returns may not be achieved. Basically, these comments are given considering the risks, uncertainties, complexities and development time involved in addition to resources required to invest into innovation projects. Lack of inclusive disciplined approach and systematic innovation process around selection of new technology projects, reduces the probabilities of innovation project's success. However, innovation or technology development is way of achieving organizational growth and sustainability. Organizations which excelling in the art of innovation are continuously achieve the strong business results compare to organizations which are having more unstructured approach. In the age of information technology, innovation and knowledge management needs more structured approach. Over the time each organization adopted certain way of working (policies and procedures), business processes and managing its business practices. However, pace of change of business environment and complexities as a results of flattening of world, it is imperative to have more agile and inclusive business strategies to sustain and grow the business. Innovation and technology adaption are one of the key means to achieve sustainable business growth. The importance of technology up-gradation, development and management is known and no need to reemphasize. The present paper suggests inclusive approach to facilitate systematic technology development, set direction for innovations, and implement robust strategy for technology development and implementation.

"Technology Roadmap" is commonly used tool in industries for depicting and planning technological ambitions of organizations. There are varieties of approach used to achieve the technology roadmap in different organizations. In order to increase probability of success of innovation programs, present paper suggest inclusive approach to new technology development and achieve set of strategic technology objectives of organization. Organization portfolio assessment must be linked to technology roadmap and to execute technology projects successfully till implementation, this paper also suggest to utilize the project management approach. Technology-driven business growth is of increasing importance to industry and nations, as a means of achieving the economic, social and environmental goals that lie at the heart of sustainable development. The effective management of technology is becoming more challenging as the cost, complexity and pace of technology change increase, in a globally competitive market. The management of technology for business and national benefit requires effective structured processes and systems to be put in place to ensure that investment in $R \& D$, facilities and skills are aligned with market and industry need of now and of the future.

"Technology management addresses the effective identification, selection, acquisition, development, exploitation and protection of technologies (product, process and infrastructural) needed to maintain [and grow] a market position and business performance in accordance with the company's objectives". Effective technology management requires a number of management processes and the definition includes the five processes proposed by Gregory (1995): identification, selection, acquisition, exploitation and protection of technology 


\section{Approaches and discussions}

The recommended inclusive approach to technology development in this paper is synergizing the Portfolio Management and setting up strategic innovation objectives $\rightarrow$ "Technology Roadmap" as a tool to depicts and plan technology development $\rightarrow$ Technology Implementation using Project Management methodology. Details of this approach is discussed in following sections.

\subsection{Inclusive approach at a glance}

1.1.1. Setting up strategic innovation objectives

Success of any program / initiative lies in the clarity of objectives set for particular initiative before the execution starts. It is observed in recent times, technology development is key strategic agenda for top management. However, the success of technology development program is highly depend of its objectives and approach to technology development. This paper suggest to use portfolio management approach. It is the responsibility of top management to assess the organization current product portfolio and its alignment with current market environment and the organizations future ambitions. Management must assess the business risks based on various market forces to their current product portfolio and requirement of future products. Top management team sets-up overall innovation and technology broad objectives are based on the assessment of business environment and business strategic objectives. The business objective like grow in mechatronics area, conventional fossil fuel products to electrical vehicle products etc.

Product portfolio assessment, innovation focus areas and strategic objectives of organizations are the foundation of technology roadmap. Technology roadmap is a tool to depict organizations technology ambitions and strategic focus areas. It is also helps to consolidate finalized technology objectives / ideas to channelize for development and serve as guide to development team. Technology road-map requires revamping if the new features or incremental adoption of technologies are added to portfolio. However, business objectives are needed fundamental shift i.e. diversification, complete business areas (e.g. fossil fuel to electric vehicles), then it is advisable to have separate technology roadmap.

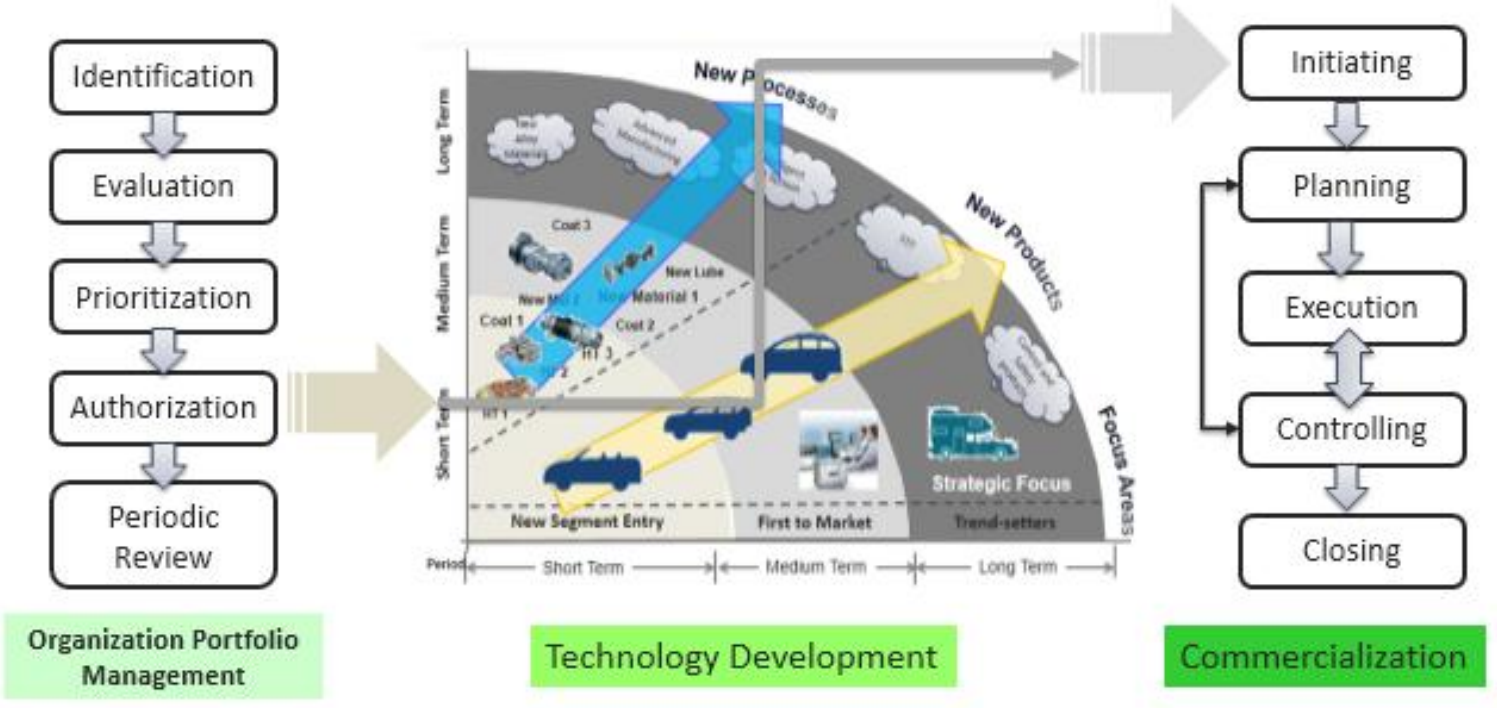

Fig 1: Inclusive Approach to Technology Development

1.1.2. Building "Technology Roadmap" (plan and develop technologies)

Technology development teams initiates, plans and develops the technologies to achieve management strategic technology objectives.

Technology roadmap servers following key purpose

- Involvement of all key stake-holders in planning process and alignment in achieving the organizations strategic objectives.

- Technology roadmap act as guiding document and provides direction to organizations R\&D teams.

- It facilitate complete alignment with future market requirements and also support prioritization of technologies development.

- Support management decision system for allocating the budgets and resources for technology development.

- Technology roadmap is an excellent tool for communicating organizations technology ambitions to external and internal stakeholders. 
1.1.3. Technology Implementation using Project Management methodology

The technologies developed and ready with organization are just a business intentional direction, however, developed technologies must be commercialized successfully to achieve business objectives.

In order to implement developed technologies project management approach to be used to ensure developed technology is align to intended business objectives. Technology implementation phase requires complete organization involvement and cross functional team approach. Suggested approach by enlarge is seems obvious and generally discussed in good organizations. However, following sections discusses each steps considerations in detail.

\subsection{Detail Discussion Of Inclusive Approaches}

\subsubsection{Steps to Portfolio Assessment}

Organization portfolio assessment and management is a continuous process. It is imperative to top management to review the portfolio systematically.

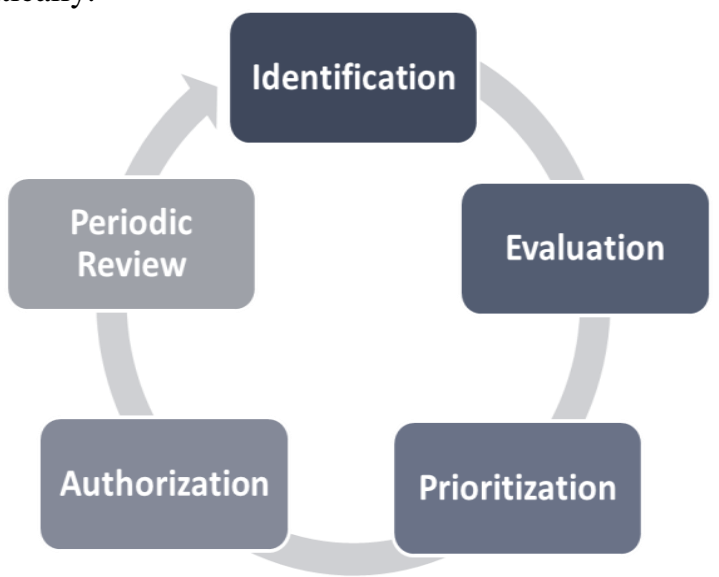

Fig 2: Inclusive Approach to Technology Development

Management should assess current product portfolio to identify the upgradations needs, competition situations and customer situation for the products in portfolio. Evaluation of identified risk, upgradations, customer and competition situation is very important to set-up direction.Outcome of the evauation calls for response to competition /customers or proactive actions from organization side to exploit or maintain the business situation. Management actions need to be prioritized for execution and also need to authorize with budget and resource. Periodic review of each action must to assess the situation as well as need for any adjustments. All the authorized actions, strategic objectives, technology upgrade or development needs are the inputs to technology roadmap.

\subsubsection{Identification}

In portfolio analysis stage identification is very important phase. In this phase management team deep dives into organizations current product / services portfolio as well as future requirements to fulfill business objectives. In this phase, customer situation, technology trends, market shifts, competition situation must be identified. Management must discuss "Business as is" and "future / desired business state" based on portfolio and identify gaps. Identify stage records new opportunities in terms of technologies, trend shift etc. as well as challenges which need to tackled. Identification stage help to gather required information for organization's future strategy and directions.

\subsubsection{Evaluation}

After compilation of required data and identifications of current business opportunities, challenges and potential opportunities, it is necessary to evaluate to understand impact and risk on the business. Evaluation stage management need to evaluate available information, business situations in-terms competition and market. Risk and opportunities are discussed and evaluated its impact on business. Management team identifies actions required to be taken to minimize the risk and exploit the opportunities.

\subsubsection{Prioritization}

All the identified actions in evaluation phases are prioritized during this phase. In this phase, actions are prioritized considering organization need, intensity of impact on business as well as resources availability including budget. The prioritization phase outcome is management team's direction to business operation. 


\subsubsection{Authorization}

All the prioritized actions, projects and new opportunity initiatives are authorized for the execution during this phase. Budget, resources and timelines are assigned for each actions as per their priority. This phase formally authorize organizations to spend resources for the achieving set business objective.

\subsubsection{Periodic Review}

Periodic review is very important to understand the progress of activities and assess need for any directional changes as necessary. Management must assess the situation and decide if certain project or initiative to be continued.

\subsubsection{Example of Portfolio Assessment}

Focus of this paper is more on the technological projects and its assessment. Here is example of steps of automotive company's product portfolio analysis. It starts with competition product portfolio analysis and understand the complete product portfolio of near competition or direct competition companies. It is recommended to categories this product portfolio based on market positioning. As mentioned in the example, it is clear identification that organization is missing convertible and van model in their portfolio. After identifying the products and services offered by the competition, it is required to compare the one's own product portfolio and identify the technological and product offering gaps with competition. This stages assessment of risk and opportunities is done. Action plan is build to mitigate the risk and exploit the new opportunities. Convertible and Van type of products are identified gap.

Prioritization of risk mitigation actions and new opportunity project is done based on various factors like availability of resources, budgets etc. Based on set criteria, organization found convertible seems more sort product in organization portfolio. Once the priotization of actions and projects are completed, the management authorized those projects for execution. In this example management authorized "convertible" vehicle building project based on portfolio analysis.

Ideal outcome of portfolio assessment should be

- Broad level strategic objective and direction of business

- Risks and Risk mitigation plan for "business as is situation" and "future state of business"

- Identified and authorized broad initiatives for technology development like light weight materials, green technologies etc.

- Resources identification and allocations based on priorities to business

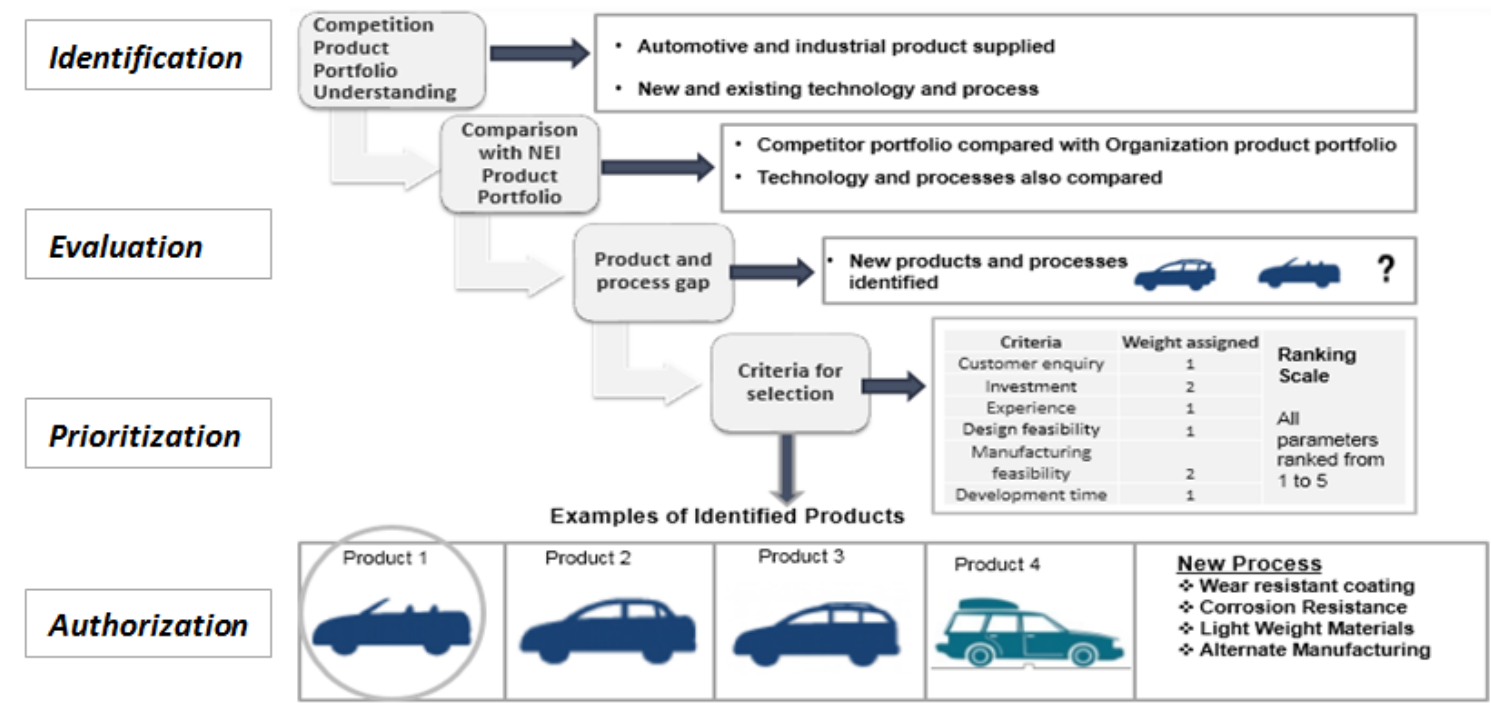

Fig 3: Example of Automotive company’s product Portfolio Assessment

\subsubsection{Steps to Technology Roadmap}

Technology roadmapping is an important tool for inclusive technology planning and collaborative process for organizations technology planning. Technology roadmapping, a form of technology planning, which facilitate organizations deal with uncertain and dynamic comeptititive market place. Technology roadmap used in organization mainly focuses on products and not all types of potential technology planning needs including processes, brand building etc. Technology roadmapping facilitate with information to management decision support system to make better technology investment decisions by identifying market driven technologies and current organizations technology gaps and identifying direction to leverage $R \& D$ investments. Technology 
investment decision are having long-lasting repercussions on organizations investments and market positions. Technology investment decision are complex in nature and technology roadmaps provides required clarity to management on technology development investments and allocation of organizations resources.

Collaborative approach to building technology roadmap, alignment with all the stake-holders makes technology roadmap robust and facilitate smooth execution and achieve the organizations technology ambitions. Following steps are suggested,

\subsubsection{Data Collection}

\subsection{External Environment Analysis}

External environment is having significant impact on business operations. External environment factors are the one which organization is not having any control. These factors are results on many factors including political, legal, social environment. It is imperative for organizations to align its technology strategy considering these factors in order to minimize risk.

\subsection{Macro-Economic factors Analysis}

Macro-economic factors like economic output, unemployment, inflation, savings and investments are important to understand high level sentiments of the nation or business environment. For example: if any organization involved in the business of earth moving machinery and if government is going to invest largely into infrastructure projects then organization should consider alignment of current products up-gradation or new products development strategies. Macro-economic factors are external factors which are controlled outside the organization and it is having impact on organization strategy and technology ambition.

\subsection{Industry trends, risk and opportunities Analysis}

It is important to understand organizations operating industry and its technology trends, purchasing pattern of customers and new entrants in the industry. All the market stakeholders must be considered in the planning like customers, competitors, supply chain partners, investors etc. The new entrants' players and new technologies brings risk as well as opportunities to organizations over technology plan. It is must to review industry trends and its impact like negative (risk) and positive (opportunities) at regular interval or at the time of technology roadmap review.

\subsection{Market technology trends in business areas}

Introduction of disruptive technologies changes the market and industry dynamics very fast. In order to be relevant and sustain in ever changing market, organizations must understand overall technology trends in the market.

\subsection{Customer "buying" pattern analysis}

Customer buying pattern understanding is the key for technology planning. In recent years buying pattern of customer changed significantly. Customer are coming more informed and aware about the product. Planning new technology introduction must be considered all aspect of technology commercialization.

\subsection{New technologies introduction}

It is important to have information of new technologies introduced in the market for technology manager to support technology roadmap decisions. Technology managers need to align, adjust or realign technology ambition based assessment of new technologies introduced in the market.

\subsection{Competition technological ambitions}

Direct and adjacent competition's technology ambitions can disrupt organizations technology planning and strategy. In order to provide required considerations, it is important to understand competitions technological ambitions. There are multiple ways one can assess and collect this information like trade shows, patent filings, external experts, supply chain partners etc.

\subsection{Competition technologies introductions in recent times}

It is important to have data of new technologies introduced by competition in recent times including new products. Reliance Jio Indian telecom company, introduced VoLTE technology network and provided complimentary experience of technology for half year. This move changed complete dynamics in the Indian telecom market. It is important to understand how and what technologies competition is launching in the market.

\subsection{Common customers perceptions and inclinations}

Customer perceptions and inclination to specific brand or service is important aspect to consider in the technology planning. It is important to consider innovation in all areas in addition to product / processes. Business model is important aspect of innovation. TATA-Sky an Indian DTH service provider given importance to it's after sales services and develop strong network which supporting building positive customer perception about the company.

\subsection{Customer aspirations in target or operating markets}

Customer aspiration is important parameters and inspiration to innovations. Integration of internet and wireless telephony technology disrupted conventional telephone market. In automobile space "infotainment" an 
integration of internet, music and real time data access technology is much sort of trend. Customers are demanding these features in the automobile even at the entry level cars.

\subsection{Customers technology ambitions}

Market is highly fragmented for automobiles and obsessed with latest technologies including ICT. Customer's ambition for technology is most important factors for technology roadmap of any organization. Indian NEXGEN (young and first car) buyers expect high end connectivity features in their car. Lack of attention to technology ambitions of customer can affect the technology roadmap and organization strategic direction.

\subsection{Customers' expectations}

In personal opinion it is a myth to consider customer always expect lower cost products or technology. Realistically, customer expects value from its purchase and amount which they ready spend on product. Technology roadmap and technologies to consider for the market must have understanding of customer's perceived value. Innovations and technology planning must consider and must be aware of customers' expectations in mind to achieve successful outcome of technology plan.

\subsubsection{5. $\quad$ Organization Internal Factor Analysis}

Organization internal factors those factors which are having no and minimal impact of external factors. These factors are within the full control of organization and its management. Management can prioritize or scale up these factors based on its strategic objectives. Organization internal factors like technical capabilities, infrastructure, budgets, priority areas, organization policies, current portfolio as well as lost customer enquiries during stipulated period is good information to considered during the technology roadmap discussion.

\subsection{Lost business / opportunities Analysis}

Lost business enquiries or opportunities analysis is good indicators to understand the organizations gaps to deliver to customer. These gaps need to be bridged in order retain customers with organization as well as align company portfolio to customer requirements. Lost business opportunities also indicate organization's position with response to current market trend and what is needed in the market. It is important for organizations technology roadmap to priorities areas where organization is need to align with customer unfulfilled requirements.

\subsection{Current portfolio Analysis}

Current portfolio analysis gives direction and also navigate technology roadmap. Portfolio need to be align with technologies trend as well as changing customer requirements. Current portfolio also helps to phase out products which are not aligned as well as add the new product to sustain organization growth and technology ambitions.

\subsection{Value mapping with respect to market and competition}

It is difficult and impractical for any business organization to meet or exceed each parameters of competition. It is always good to assess and understand the values (USPs) of competition and map with one's own organization. This understanding support organization to build on its own strengths and also accept certain weakness. Example, if competition is having large product portfolio which seems difficult to match in short time and also not getting aligned to organization strategy, then it is better to accept it. However, this analysis supports organization to understand its own strength areas vis a vis competition and build on it. Market dynamics keeps changing and if technology roadmap align and address with changing market requirements, it is possible to overcome the weak areas and build new strengths for organization.

\subsection{Organizations strategic objectives}

It is very important to have clear alignment of organization strategic objectives and technology ambition of organization. Strategic objective of organization provides direction and support technology projects prioritization. Clarity of strategic objectives and technology projects selection as well as prioritization based on these objectives, likely to support to allocate resource and execute the projects.

\subsection{Internal marketing teams inputs}

Inputs from internal sales team are invaluable insights of business environment. Alert and attentive sales team can gather lots of customer and market business information which may be difficult to get from formal channels. Sentiments of customers and unaddressed needs can be thoughtful inputs and consideration during the technology roadmap and project selection.

\subsection{Inputs from brainstorming workshops and ideas database}

Organization knowledge assets like brain storming workshop's inputs and ideas data base are key resource to gather list of potential projects. It is always a good idea to have this information available during the technology roadmapping discussions.

\subsubsection{Data Analysis and Evaluation}

Post data collection phase, data need to be evaluated for meaningful interventions. Collected data is of no use if the data is not properly analyzed and evaluated for intended objective. In case of technology roadmap, data must be analyzed to understand the trends, customer preferences and potential future customer requirement in order to align technologies for development. 


\subsection{Market potential Analysis}

Market potential analysis to be considered on understanding changing market dynamics and potential for any new technologies in the market. Market potential analysis is done for understanding impact of known new technologies and impact because of potential disruptive technologies. Known new technologies impact on organizations business is comparatively easy to analyze. However, unknown or disruptive technologies impact is difficult to analyze. However, data analysis purpose both the parameters to be considered. Market attractiveness and time to market are the two important dimensions for achieving commercial success from technologies.

\subsubsection{2. "Business As is" Vs. "Business to be" analysis}

The fundamental purpose of technology roadmap is to guide business growth ambition with technology. Technology roadmap is strategic document which facilitate organizations to visualize and pursue organization growth ambition. It is very important to visualize "business as is" (present state) situation based on available data and analyze the gap between organization growth ambition and achievements. "Business as is" situation needs to be compared with "business to be (future state)". Technology projects are the means to bridge the assessed gap. Technologies which are having higher potential for filling this gap and achieve "business to be" situation must be given higher priorities.

\subsection{Short-listing of ideas}

Organization's idea data base, ideas collected during the data collection phase, potential technology list etc. are the resources for ideas short listing. Ideas to be shortlisted based on market potential of the ideas and also how it is going to support business to be situation. In addition market potential and growth, due consideration to be given to development lead time, resource requirements - human resources, skills, capabilities and budget etc. Metrics to be formed and qualitative ranking to be completed to arrive at the shortlist of ideas.

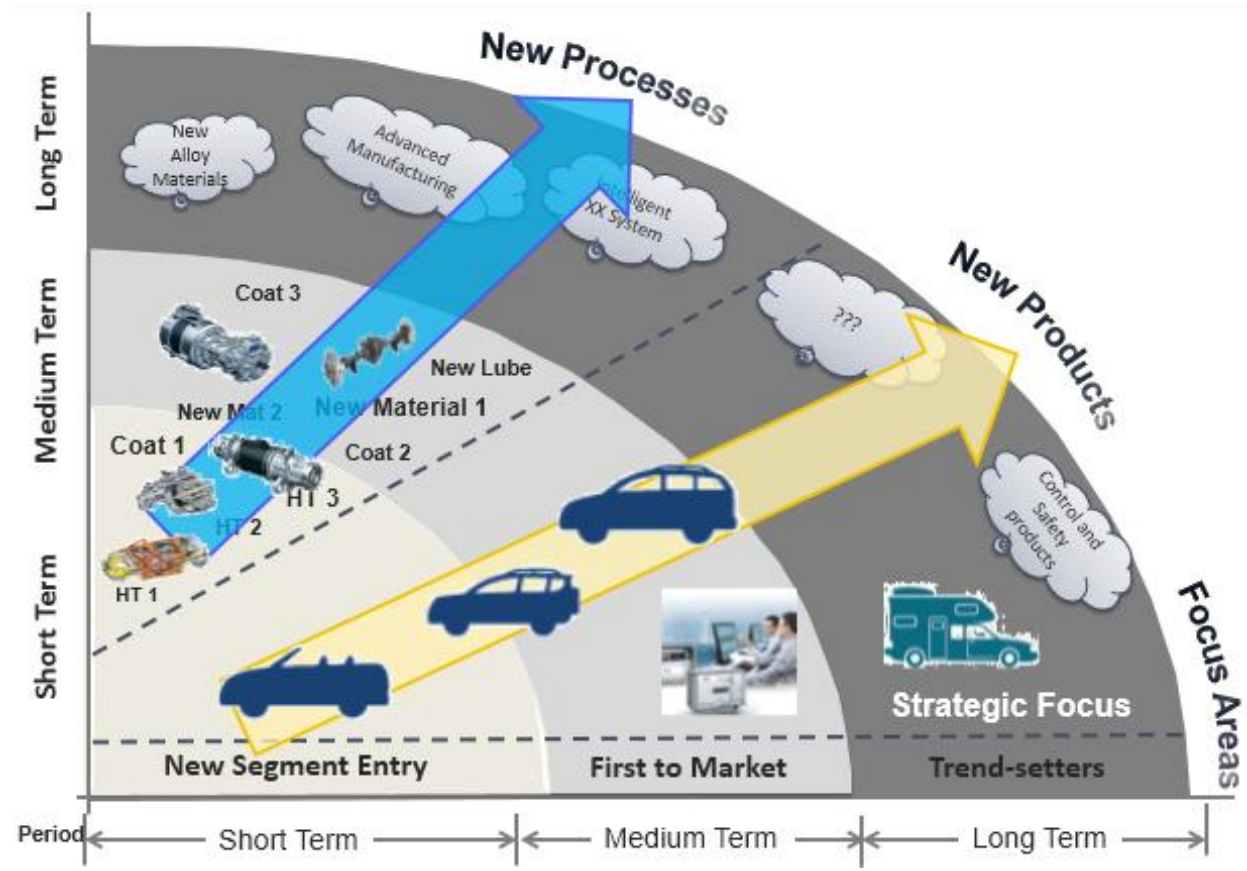

Fig 4: Example of typical Automotive company’s technology roadmap

\subsubsection{Sequencing and timelines for technologies}

Analyzed and evaluated technology ideas need to be sequenced and development timelines to be estimated. Technologies development project will be placed on technology roadmap horizons based on its development lead time and sequence defined during this phase. Generally, longer duration project with better market potential should be sequenced first and resource allocated appropriately.

\subsection{Development duration compilation}

Estimation of development lead time for each short listed technology development project is important. Estimation of development lead time to be assessed based on in-house development as well as other possibilities like joint development, collaboration possibilities etc. Based on the development lead time and market launch requirements appropriate prioritization and sequencing of project to be worked out. 


\subsection{Organizational Resources Analysis}

It is important to step to analyze organizations resources and their capabilities for short list technology projects. Technology development projects requires resources which may be available in the organization and also new skills or resources are need to acquire. Based on analysis of resource and its availability projects to be sequenced. Basically, projects which are can be started with available resources, should be given priority.

\subsection{Sequencing of technologies}

Metrics to be prepared based on development lead time and resources required for the project. Score of the project based to development lead time and resources requirements project can be sequenced for development and accordingly positioned in technology roadmap. Sequence of project in technology roadmap is indication of its priority for development. Sometimes, in order to achieve bigger project many small or multiple duration projects needs sequencing in the roadmap to align with bigger objectives. Example: If any automotive organization is planning to launch electric vehicle, however, current product portfolio is largely aligned to fossil fuel vehicle technologies, then organization must have plan for power train development for electric vehicle. The powertrain development project will be sequenced ahead vehicle program.

\subsubsection{Detailed Technology Development Execution Planning}

As depicted in the fig 5, sequencing of project is based on larger objective to achieve. In order to launch convertible program organization need to find out gap in current available technologies and final intended product. Based on gap analysis light weight material and power train development project are sequenced. Considering organization is having required know-how to build vehicle, as soon as power train is developed it can start the vehicle building program and achieve the desire goal. Vehicle development program without powertrain will be largely out of sync to organization objective.

Typical example of automotive company's technology project sequencing is depicted in Fig 5.

\subsubsection{Steps to generate and convert ideas into successful technologies}

Success of technology development lies in combination of creativity, discipline and structure of technology development projects. Most of the technology projects do not deliver as expected mainly because of lack of discipline and structure than the creativity itself. However, creativity phase is also important phase of technology development.

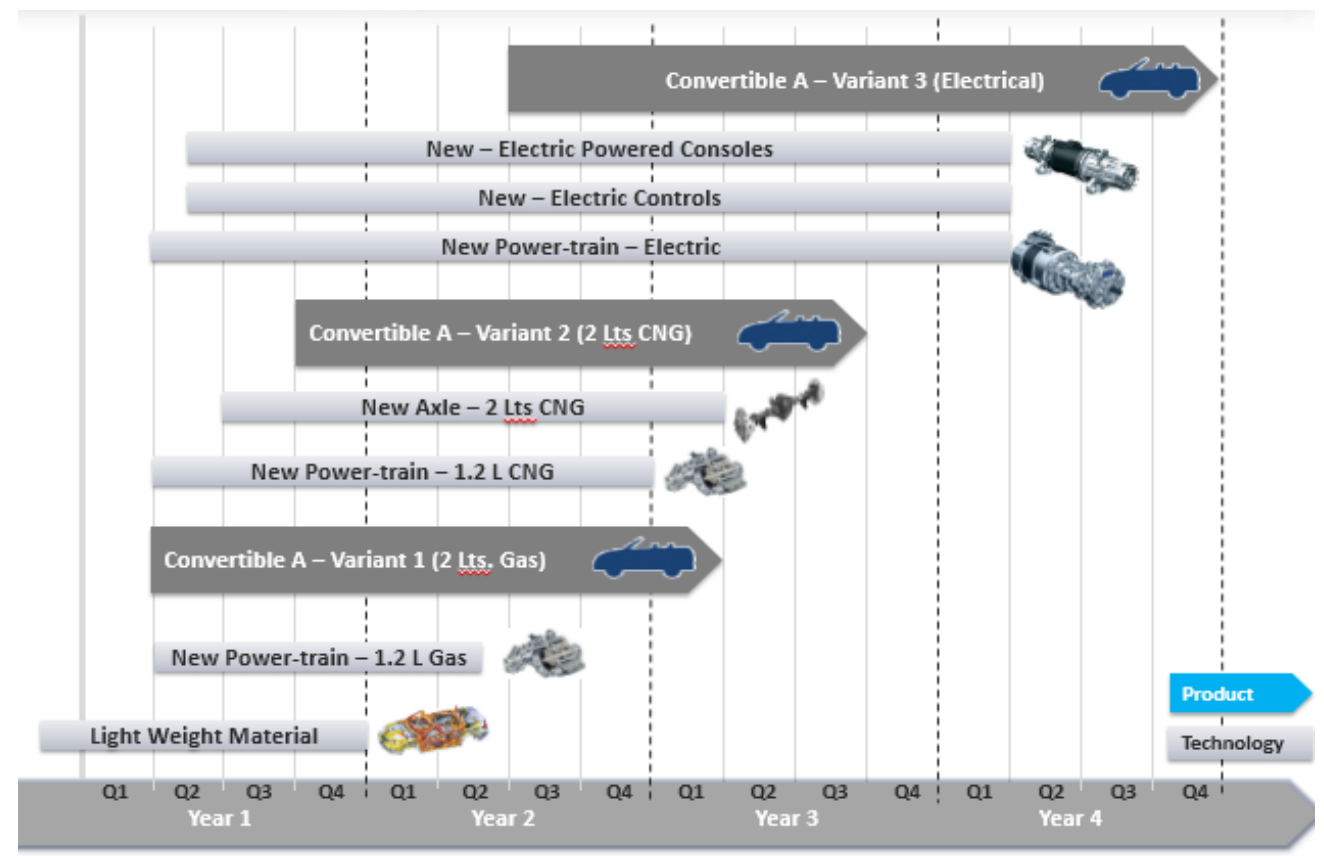

Fig 5: Example of Automotive company's new technology project sequencing

After short list of technology for development, 4 steps are recommended for successful technology development,

a) Ideation Phase:

Even though technology ideas are short listed and planed during the technology roadmapping phase, detailing of idea is being done during the ideation phase. In this phase team need to understand the details of requirements, 
customers' expectations using tools like QFD. Ideas to be generated specifically to achieve the desired objective of the technologies and all these generated ideas to be evaluated and selected for the implementation.

Risk assessment and its mitigation plan is most important activity of this phase. This phase defines details of all the technology expectation, deliverable and acceptance criteria during execution phase.

b) Development phase

Basically at this stage, execution plan is prepared including detail time-plan, resources requirements, trainings etc. is proposed to and approved by the management. In this stage, all the concept and engineering activities are completed. Mathematical modeling or simulations etc. are carried out and ideas takes shape to build hardware i.e. prototypes etc.

\begin{tabular}{|c|c|}
\hline Ideatic & $\begin{array}{l}\text { - Requirement understanding, QFD } \\
\text { - Idea Generation, Ranking, Evaluation, Selection } \\
\text { - Risk Analysis and Mitigation Planning, IP } \\
\end{array}$ \\
\hline Develop & $\begin{array}{l}\text { - Execution Plan, Budget, Resources, Trainings } \\
\text { - Execution, DOEs, Mathematical Modeling, Engineering Documentations }\end{array}$ \\
\hline Verify & $\begin{array}{l}\text { - Processes, Prototypes, Virtual Validations, DVPs } \\
\text { - Testing - Lab, Field, Customer Experience }\end{array}$ \\
\hline Hand- & $\begin{array}{l}\text { - Technical Documents - Design guidelines, Mathematical Models, Lessons } \\
\text { Learned } \\
\text { - Marketing team training, Penetrate }\end{array}$ \\
\hline
\end{tabular}

Fig 6: Steps to successful technology development

c)

Verification phase

New technology projects need more effort to verify the claims of technologies as well as establish the methodology to verify the claims which are acceptable. In case of breakthrough technologies and disruptive technologies the challenge is to satisfy internal organization standard in addition to market requirements. In this phase prototypes are built and tested as per designed criteria. Major portion of budget is utilized during development and verification phase. Sometimes accredited labs certifications and testing report are necessary to meet prescribed legal requirements if any.

d)

Handover phase

In order to commercialize and develop market specific variants, technology know-how to be handed over the product engineering team. Product engineering team or commercialization team is responsible to product management until phase out stage of the product. Fundamental know-how comes from technology development team, however, product engineering team will utilize this know-how and organizations procedures and systems for building market specific product variants as well as upgrades as needed. This team will support business development team and operations team to resolve any product related issues. All the documents technical and non- technical to be handed over the product engineering team for further utilization. Product engineering team may utilized developed technologies as appropriate to other products as well.

\subsubsection{Steps to successful technology implementation}

In many organizations, technology development projects are executed in autonomous environment which is mostly independent of current business on goings. Technology development and horizontal deployment of technology needs different ways of handling. Technology development processes may not be considering factors like expected volume, pricing, customers, variants, capital investments, manpower, productivity etc. However, these factors are very important factors for successful technology implementations and continued business considerations. Successful technology implementations process needs considerations from customer to customers and their requirements. Technology development is done keeping customers major requirements in mind, however, specific customers' requirements need to be considered and fulfilled at technology implementation stage. 


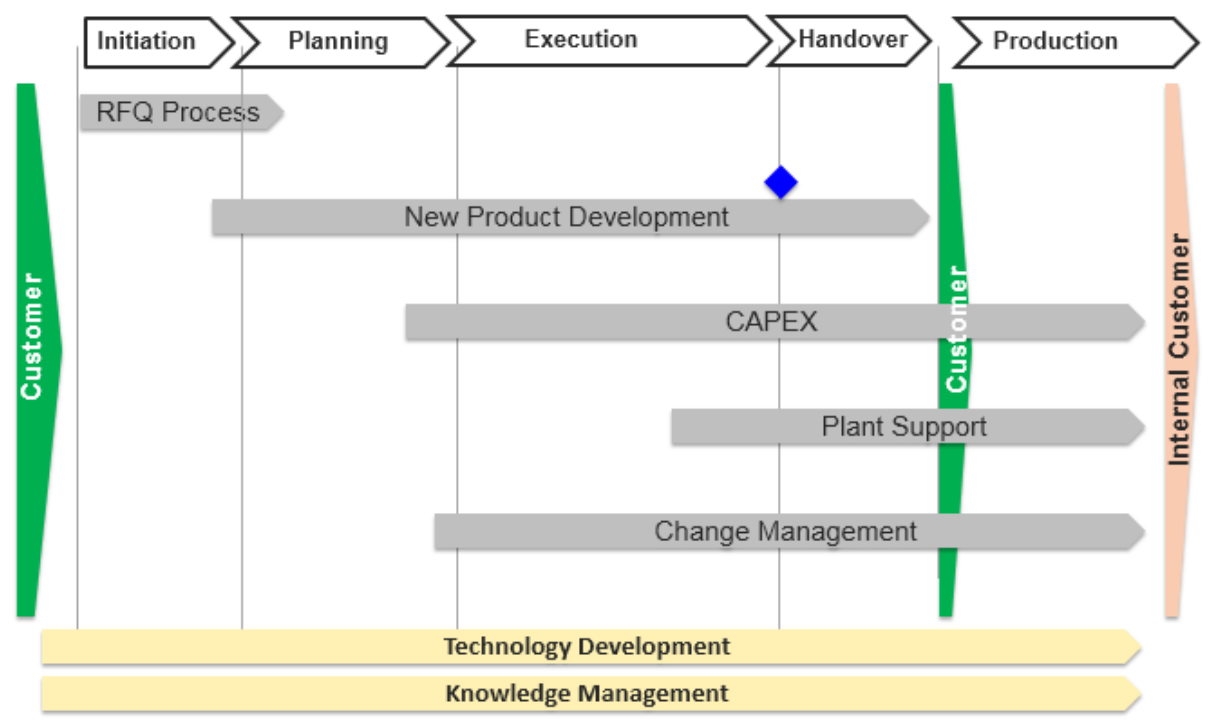

Fig 7: Steps to successful technology implementation

Typically, technology implementation stage start with customer "Request for Quotation (RFQ)" or enquiry to organization possessing the technology. After fulfillment of all the condition of RFQs and mutual agreements, new project starts formally for implementation of technology, also called as new product development. Based on product requirements and technologies new capital investment in-terms of machinery, tooling etc. initiated for mass production of product. Additionally, as the mass production start organization need to implement team for plant support which includes continues improvements, plant maintenance as well as other productivity improvement projects. As the technology start getting into the field and over the time, based market feedback there is always need to change management and adopting product changes to changing market requirements. Knowledge management and technology development functions need to work all along and keep developing the technologies based on market knowledge of new technologies and changing customer requirements. Basically, successful implementation of new technology projects start with customer requirements understanding and meeting the same with organizations processes and systems consistently by fulfilling internal customer requirements and implementing the changes as appropriate in controlled environment.

\subsubsection{Steps to Technology Project Management}

Project management methodology is suitable approach for implementing technology projects. Basically, project management consist of five phases. Technology projects initiates with basic information about the project and product's technical requirement and seeks approval from management. Planning phase details the project plan including scope, time and budget. In addition to scope, time, budget it is also important to consider quality, risks and customer satisfaction parameters in order to capture all the project requirements and planned for the perceived risk to project.

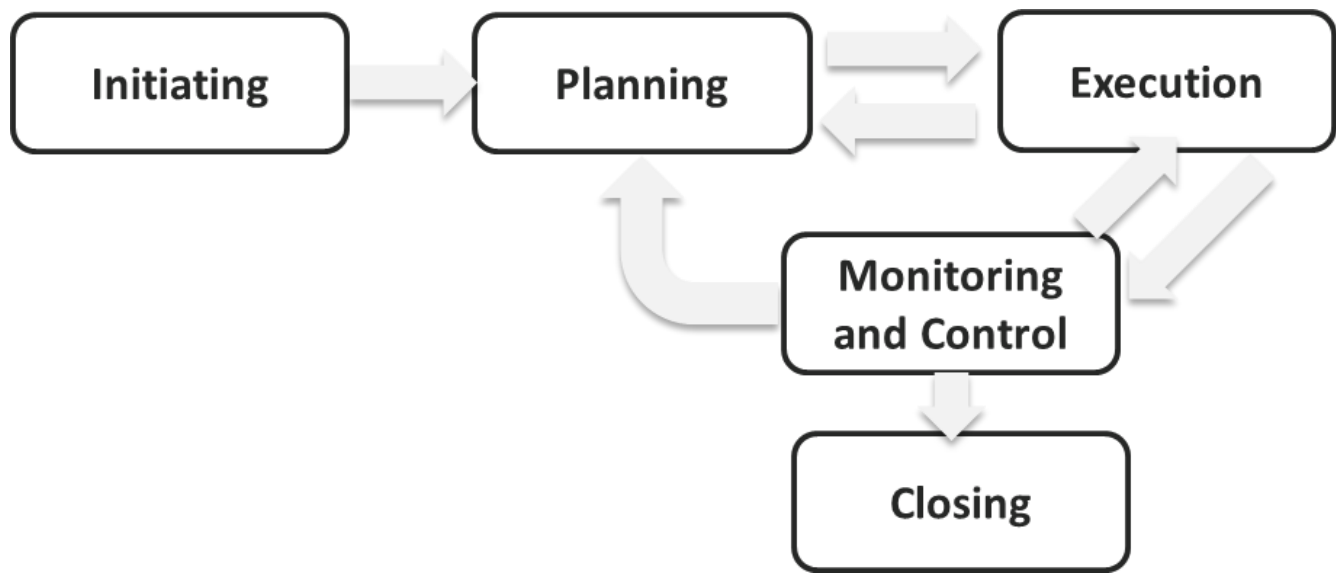

Fig 8: Typical Project phases 
Properly planned project is having high probability of smooth execution and ability to tackle any unforeseen events during the project. In-spite of good plan it is very important to monitor and control the key events in the project so that project is always running as per the plan and no new risk are arises. Organization must close the project formally and document all the key finding of the projects and close the project formally. Formal closing of the project provide good learnings and guides of next projects.

\section{Conclusion}

Technology development projects must be aligned with business objectives in order to achieve the strategic goals / objectives of the organizations. Inclusive approach proposed in present work facilitates organization technology planning process till its successful implementation. Portfolio analysis based on organizations strategic objectives supports for technology roadmap and selection of suitable projects to achieve the strategic objective. Selection of technology projects should be based on the proposed approach i.e. data collection, analysis and evaluations, sequencing of project based on resources and development time provide basis for project selection. After selection of technology and management approvals to technology roadmap, technology project to run using steps of ideation, develop, verify and handover. Once the technology projects are handed over to implementation team, implementation and scaling of technologies for business revenue generation recommended to use project management methodology in which project to be planned in detail and executed in structured manner. Breakthrough and disruptive innovations are having uncertainties and unknown, structured approach proposed helps in reducing the risk and control the impact of risks if occurs during development process. In case of incremental innovations, risks to certain extent are known so it is recommended to follow the same process for implantations using organizations established processes. Structured approach and discipline steps increases probability of success of technology development projects as well as achievement of organizations strategic objectives.

\section{Acknowledgement}

Authors express his sincere gratitude to NEI team members and colleagues for their contribution and views for this paper.

\section{References}

[1]. Albright E Richard, A Unifying Architecture for Roadmaps Frames a Value Scorecard (2003) Retrieved from http://www.albrightstrategy.com/papers/Albright-IEMC2003.pdf

[2]. Albright E. Richard, What Can Past Technology Forecasts Tell Us About the Future?, Technological Forecasting and Social Change. Jan 2002. Retrieved from: http://www.sciencedirect.com/science/article/pii/S0040162502001865

[3]. Phaal Robert, Technology Roadmapping, Centre for Technology Management, University of Cambridge, United Kingdom (2003) Retrieved from: http://www.unido.org/fileadmin/import/16963_TechnologyRoadmapping.pdf 